\title{
Guidance Molecules in Synapse Formation and Plasticity
}

\author{
Kang Shen ${ }^{1}$ and Christopher W. Cowan ${ }^{2}$ \\ ${ }^{1}$ Department of Biology, Howard Hughes Medical Institute, Stanford University, Stanford, California 94305 \\ ${ }^{2}$ Department of Psychiatry, The University of Texas Southwestern Medical Center, Dallas, Texas 75390-9127 \\ Correspondence: christopher.cowan@utsouthwestern.edu
}

A major goal of modern neuroscience research is to understand the cellular and molecular processes that control the formation, function, and remodeling of chemical synapses. In this article, we discuss the numerous studies that implicate molecules initially discovered for their functions in axon guidance as critical regulators of synapse formation and plasticity. Insights from these studies have helped elucidate basic principles of synaptogenesis, dendritic spine formation, and structural and functional synapse plasticity. In addition, they have revealed interesting dual roles for proteins and cellular mechanisms involved in both axon guidance and synaptogenesis. Much like the dual involvement of morphogens in early cell fate induction and axon guidance, many guidance-related molecules continue to play active roles in controlling the location, number, shape, and strength of neuronal synapses during development and throughout the lifetime of the organism. This article summarizes key findings that link axon guidance molecules to specific aspects of synapse formation and plasticity and discusses the emerging relationship between the molecular and cellular mechanisms that control both axon guidance and synaptogenesis.

\section{SYNAPTOGENESIS AND NEURONAL SYNAPTIC PLASTICITY}

$\mathrm{D}$ uring neuronal development, extending axons navigate to stereotyped target regions in the brain and body with the ultimate goal of making a functional synaptic connection. The chemical synapse represents a specialized functional and morphological cell structure where a presynaptic neuron communicates with the postsynaptic cell. For most neurons, an action potential in the presynaptic axon stimulates the controlled release of chemical neurotransmitters that bind and activate specific receptor proteins that reside on the postsynaptic and presynaptic membranes. This triggers the opening of ion channels and activation of signaling cascades. There are numerous types of synapses, often characterized by the type of neurotransmitter released from the presynaptic terminal and the specific cell types involved. As a central aspect of neurobiology, there are vast numbers of studies focused on synapse formation, synaptic physiology, and circuit organization and function. The purpose of this article is

Editors: Marc Tessier-Lavigne and Alex L. Kolodkin

Additional Perspectives on Neuronal Guidance available at www.cshperspectives.org

Copyright (C) 2010 Cold Spring Harbor Laboratory Press; all rights reserved; doi: 10.1101/cshperspect.a001842

Cite this article as Cold Spring Harb Perspect Biol 2010;2:a001842 
to focus on recent findings that implicate axon guidance-related proteins in the processes required for synapse formation and plasticity.

Much like axon guidance, the process of forming a new synapse (Fig. 1), or synaptogenesis, involves coordinated cell morphological and structural changes that are instructed through ligand-receptor interactions, intracellular signaling cascades, and complex filamentous actin (F-actin) remodeling. There are also cell intrinsic processes that contribute to the pre-establishment of synaptic components long before the dendrite or axon arrives at future synaptic sites, or that prohibit formation of inappropriate synapses. The processes that govern how, when, and where a synapse will form, and specifically, the cell and molecular mechanisms that control synaptogenesis, are still poorly understood. During the past two decades, technological advances in microscopy and the use of modern molecular and genetic approaches have allowed for basic characterization of key steps in synapse formation and plasticity. Much of our knowledge of synapse formation is based on analysis of either the neuromuscular junction (NMJ) or the glutamatergic axo-dendritic synapse formed between two neurons. However, it is likely that each subtype of synapse, such as an inhibitory (e.g., GABAergic), neuromodulatory (e.g., dopaminergic), or excitatory (e.g., glutamatergic), has distinct mechanisms controlling its formation and plasticity. In fact, there are substantial differences in the processes and molecules involved in the two most studied synapses, the cholinergic NMJ and the glutamatergic central synapse.

For the purposes of this article, we have chosen to focus in large part on the axodendritic synapse as many guidance-related molecules play a role in these types of synapses. For simplicity, we have also organized the basic steps of synapse formation into the following categories: (1) synaptic prepatterning, (2) dendritic filopodial motility, (3) contact stabilization, and (4) synaptic maturation. In addition, functionally mature synapses are not static, but instead alter their strength and number in response to experience to facilitate complex behavioral plasticity.
In this article, we discuss a wealth of literature that indicates an important role for many axon guidance-related proteins in synapse formation and plasticity. Although dual functions for axon guidance molecules in synapse formation may be an efficient use of existing axonal and dendritic proteins, it is interesting how the same proteins can regulate such diverse cell biological processes. Exploring this issue will be an important area for future research.

\section{AXON GUIDANCE AND SYNAPSE FORMATION}

There are numerous similarities between axon guidance and synapse formation/plasticity. Obviously, the targeting of axons to the appropriate target field is an essential process for proper neural circuit formation, and the axon is an obligate partner of the functional synapse. Axon guidance involves the interaction of receptor proteins found on the surface of navigating growth cones with secreted or cellsurface-bound ligands encountered en route to, or in, the target field. Binding of ligand to receptor often stimulates intracellular signaling cascades that coordinate complex cell morphological changes in the axon growth cone to move toward (attraction) or away from (repulsion) the guidance cue source. Similarly, the interaction between an axon and a postsynaptic cell appears to trigger signaling events necessary for synapse formation, and in some cases, involves complex morphological changes that are largely mediated by regulated assembly and disassembly of the F-actin cytoskeleton. Regulation of F-actin dynamics is a major process controlling the morphological changes in both navigating growth cones and in dendritic spines. Spines represent the site of $\sim 90 \%$ of excitatory glutamatergic synapses in the mature vertebrate brain, and whereas the precise role of dendritic spines is still debated, it is likely that they play an important role in proper synaptic transmission. As such, there are numerous lines of research seeking to understand the mechanisms that control dendritic spine formation and remodeling. 


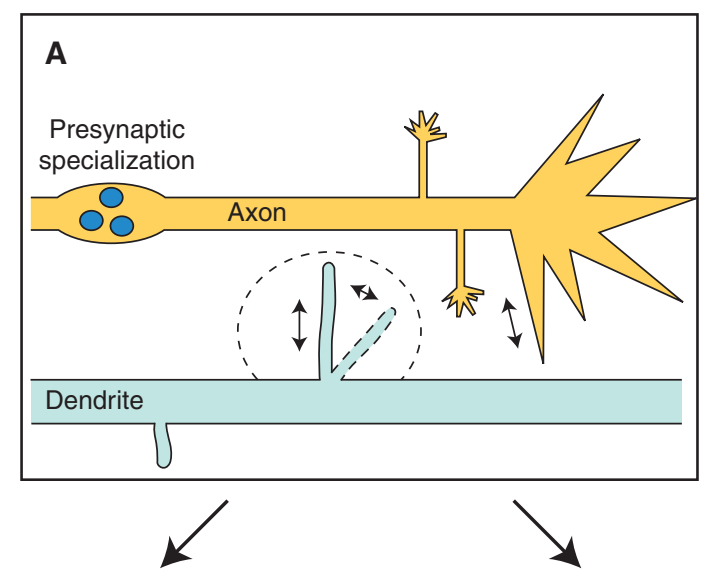

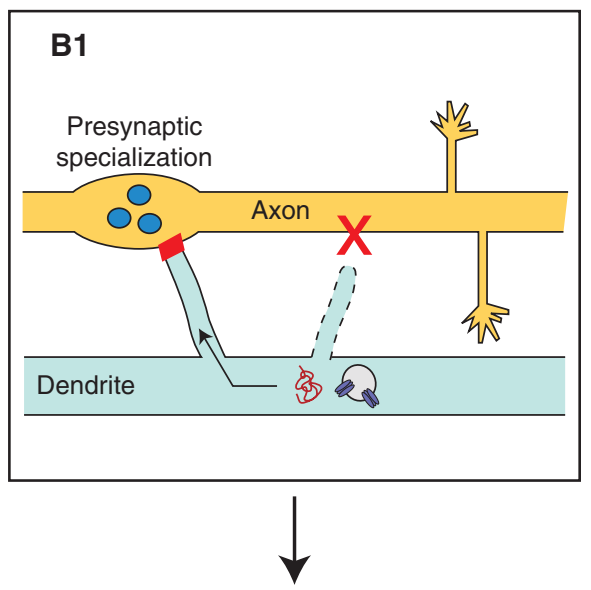

B2
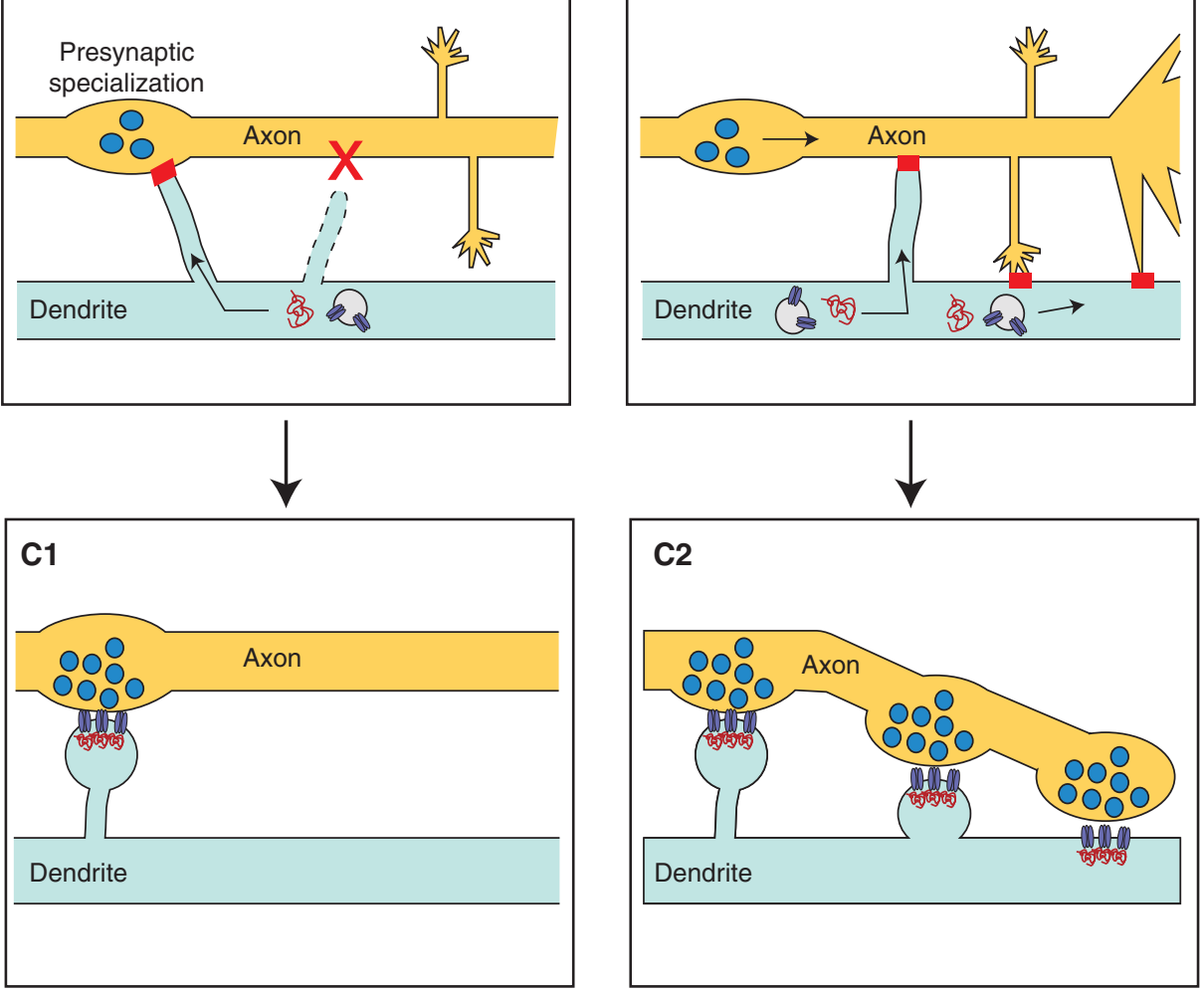

C2

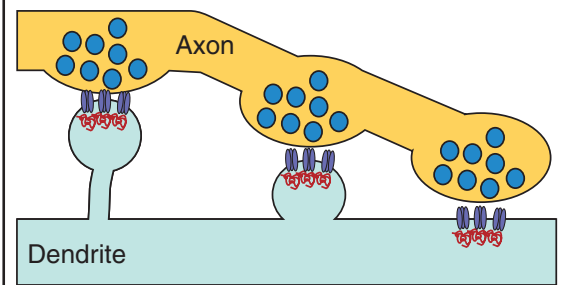

Figure 1. Basic steps of axo-dendritic synaptogenesis. Diagrams illustrate key steps involved in forming generic central synapses. (A) A guiding axon and nearby dendrite interact via cell-cell contacts mediated by the growth cone, collateral axon branches, or dendritic filopodial extensions. (B1) In some scenarios, pre-established presynaptic specializations mark the location of future synapses, whereas inappropriate axonal regions do not allow for synapse formation. (B2) In another scenario, random physical interactions between axon and dendrite (red boxes) form transient cell-cell adhesions. If the contacts are stable, then presynaptic and postsynaptic proteins, vesicles, and ion channels are recruited to the contact site. (C1 and C2) Stable contacts are matured into functional and morphological chemical synapses (spine or shaft synapses). 
Another similarity between axon guidance and synapse formation/remodeling is the compartmentalization of signaling events. In the navigating axon, guidance cues initiate localized changes in the growth cone morphology that promote axon outgrowth or turning (attraction or repulsion). Similarly, a dendritic spine provides a morphological subcompartment of the dendrite that may restrict synaptic activityinduced signaling events to the activated spine synapse. However, it is important to note that dendritic spines are not absolutely necessary for synapse-specific compartmentalization as shown in aspiny neurons (Goldberg et al. 2003; Soler-Llavina and Sabatini 2006).

In an axon growth cone, rapidly extending and retracting filopodial structures are thought to search the local environment for guidance cues. Similarly, highly dynamic, dendritic filopodia extend from the dendritic shaft during the robust periods of synaptogenesis, and appear to search the proximal space for a potential presynaptic axon in the vicinity. This process likely increases the probability of making axo-dendritic contacts and forming functional synapses. However, the physical interaction between dendritic filopodium and axon is not sufficient to induce a synapse as many contacts are transient. Like growth cone navigation, cell-surface proteins and intracellular signaling pathways likely determine whether an axo-dendritic interaction proceeds to form a synapse or whether the contact is "repelled." In some cases, the axon "attracts" the dendrite to form synapses in specific regions (see later).

\section{SPECIFIC ROLES OF GUIDANCE MOLECULES IN SYNAPTOGENESIS}

\section{Synaptic Prepatterning}

Two distinct types of synapses can be categorized based on where the synapses locate within the axon: terminal synapses and en passant synapses. Terminal synapses are formed at the end of the axon projections, whereas en passant synapses locate along the axon shaft and can be far away from the axon terminal. Both types of synapses are quite abundant in both the vertebrate and invertebrate nervous systems. For example, the vertebrate NMJ comprises terminal synapses because motor neurons only elaborate synapses at their terminal arbors. For the most part, invertebrate synapses are formed en passant, and there are many examples of en passant synapses in the vertebrate CNS.

Although the locations of terminal synapses are governed by proper axon targeting to the future synaptic site, the precise locations of en passant synapses are determined independently from growth cone guidance. During synapse formation, it is generally thought that the dynamic movements of dendritic filopodia initiate the contacts between the axon and its postsynaptic partners (see Fig. 1B2). However, there is also evidence that an axon possesses intrinsic abilities to pattern its presynaptic terminals. For example, in dissociated cortical neurons, the initial formation of presynaptic terminals occurs preferentially at predefined sites within the axons (Fig. 1B1). Transporting synaptic vesicle precursors pause repeatedly at these sites, even in the absence of neuronal or glial contact, and "attract" dendrite filopodia to form stable synapses (Sabo et al. 2006).

If axons can independently pattern their future presynaptic terminals, what factors control this process? The Caenorhabditis elegans DA9 motoneuron elaborates around 25 en passant presynaptic boutons in stereotyped locations along its axon. These presynaptic specializations are found exclusively within a short segment in the middle of the axon trajectory. Genetic analyses showed that two diffusible extracellular gradients formed by the axon guidance ligands, LIN-44/Wnt and UNC-6/netrin, play instructive roles in preventing formation of inappropriate presynaptic specializations outside of the middle axon segment. LIN-44/ Wnt functions through a frizzled receptor, LIN-17, whereas UNC-6/netrin acts through the UNC-5 receptor (Klassen and Shen 2007; Poon et al. 2008). Interestingly, both UNC-6/ netrin and LIN-44/Wnt also participate in DA9 axon guidance through persistent gradients. A gradient of UNC-6/netrin expression (high ventral/low dorsal) repels dorsal axon migration using the repulsive UNC-5 
receptor (Hedgecock et al. 1990); whereas, a posterior-anterior gradient of LIN-44/Wnt guides the anterior turn of the axon (V. Poon and K. Shen, unpubl.). Therefore, the same extrinsic cues provide positional information for two distinct cell biological events during development.

Much like growth cone guidance, local attractive cues appear to promote synapse formation. Recent findings suggest the existence of guidepost cells, which ensure the stereotyped location of certain synapses and help coordinate the proper formation of neural circuits (Fig. 2) (Chao et al. 2009). For example, in nematode C. elegans, the thermotactic interneuron, AIY, forms stereotyped synaptic connections onto the interneuron, RIA. These synapses are formed in dyadic fashion with another set of interneurons, RIB, such that the AIY presynaptic terminal faces the two dendrites of RIA and RIB in the synaptic complex (White et al. 1986). Therefore, the AIY axon needs to find both of its postsynaptic targets at the same spatial coordinate. This synaptogenesis process is controlled by glial-like ventral cephalic sheath cells (VCSCs), which serve as guidepost cells. The thin processes of VCSCs use UNC-6/netrin to define the location of synapses and to coordinate the formation of the synaptic complex. However, UNC-6/netrin appears to have distinct effects on the presynaptic AIY and the postsynaptic neuron RIA. For AIY, local secretion of UNC-6/netrin stimulates the formation of presynaptic terminals next to the VCSC, whereas UNC-6/netrin attracts RIA dendritic outgrowth toward the VCSC (Colon-Ramos et al. 2007). Intriguingly, these distinct cellular responses are mediated by the same receptor, UNC-40/DCC. Taken together, these findings suggest that axon guidance, presynaptic specialization and dendrite outgrowth are intrinsically coupled by the common molecular cue, UNC-6/netrin. UNC-6/netrin uses two distinct receptors, UNC-40/DCC and UNC-5, in these processes to regulate axon guidance and synaptogenesis. In both events, UNC-40/DCC seems to confer attraction of growth cones or local construction of synapses, whereas UNC-5 is required for repulsion of axons and
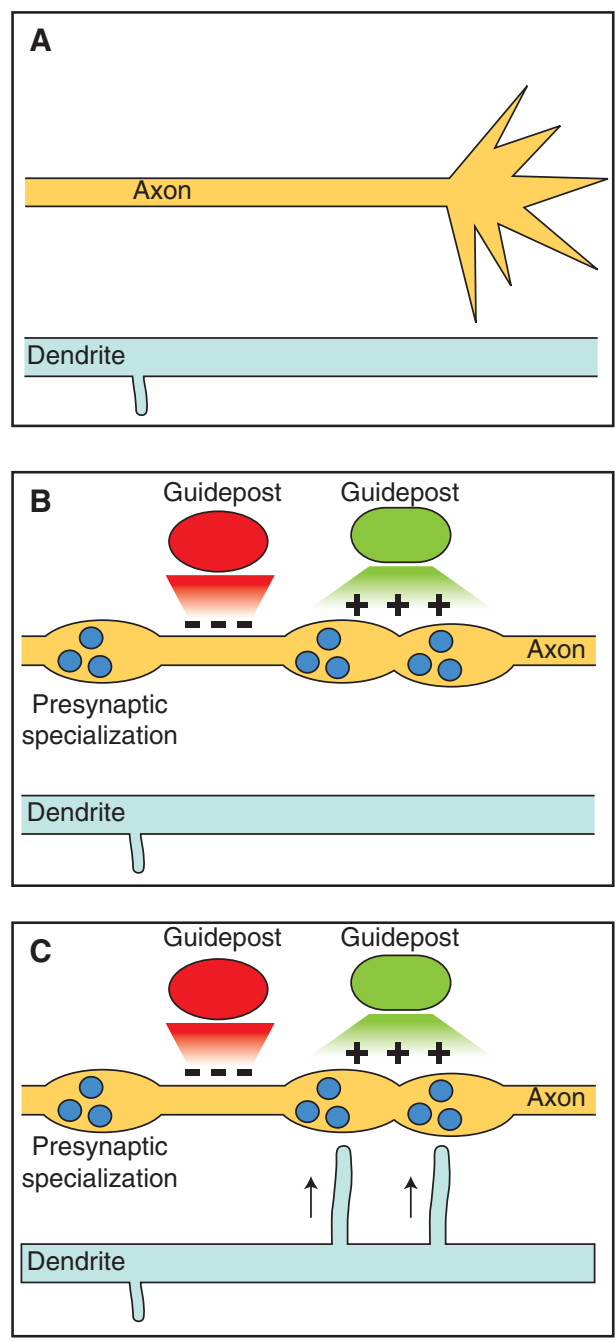

Figure 2. Prepatterning of synaptic specializations. Diagrams show the time-course of one form of synaptogenesis for en passant synapses. (A) An undifferentiated axon and dendrite before synapse formation. (B) Extrinsic cues promote (green) and inhibit (red) local presynapse formation, thereby patterning the subcellular localization of presynaptic terminals. $(C)$ Postsynaptic dendritic filopodia approach presynaptic specializations to form synapses.

exclusion of synaptic material (Colon-Ramos et al. 2007; Poon et al. 2008).

How could the same morphogenetic gradients play instructive roles for both axon guidance and synapse formation? Both axon guidance and patterning of presynaptic specializations can be viewed as symmetry breaking 
processes. During axon guidance, actin polymerization is favored in subareas of the growth cone facing the attractive guidance molecules, which likely underlies growth cone turning. In contrast, synapse formation involves the transformation of an undifferentiated patch of presynaptic plasma membrane into a highly organized membrane-protein complex specialization. Perhaps a polarized gradient of extrinsic cues specifies the synaptic location by initiating the formation of a localized protein complex that recruits and captures presynaptic machinery (Fig. 2). Consistent with this idea, the interaction between certain cell adhesion molecules, such as neuroligin/neurexin and SynCaM, are sufficient to initiate presynaptic formation (Yamagata et al. 2003). Alternatively, graded regulation of synaptic vesicle trafficking might also result in specific localization of synapses. Future analysis of the downstream signaling mechanisms will likely provide important new insights.

\section{Filopodial Motility}

Dendritic filopodia and spines were first observed over a century ago. However, the essential role of these morphological structures has remained unclear. Detailed time-lapse and ultrastructural analysis of dendritic filopodial structures has revealed that they are rapidly formed, but are very unstable in young neurons (mean lifetime of minutes to hours [Ziv and Smith 1996; Trachtenberg et al. 2002]). They are very abundant on most neurons during early development, but as neurons mature, dendritic filopodia numbers decline dramatically, whereas the number of dendritic spines, which are morphologically distinct and more stable structures, and functional synapses increase (Fiala et al. 1998). The energy involved in generating dynamic filopodia suggests that they must play an important role in synaptogenesis, but they do not appear to be essential for a synapse to form. Highly motile dendritic filopodia likely survey the proximal dendritic space to increase the probability of interacting with a synaptic partner (axon) and thereby increase the number of synapses formed. Interestingly, the axon guidance molecules, BDNF/TrkB and EphB2, appear to facilitate axo-dendritic synaptogenesis, at least in part, by controlling dendritic filopodia motility.

\section{BDNF/TrkB}

The neurotrophic factor, brain-derived neurotrophic factor (BDNF), and its high-affinity receptor, tropomycin-related kinase B (TrkB), are key mediators of axon guidance, synapse formation, and plasticity (Huang and Reichardt 2003; Luikart and Parada 2006; Lu et al. 2008) (Fig. 3A). Numerous studies have reported BDNF-induced changes in dendritic spine density and morphology in a variety of neuron populations. Consistently, TrkB-deficient mice have significantly fewer dendritic spines and excitatory synapses on CA1 hippocampal neurons, because of a postsynaptic and cell autonomous role for TrkB during a defined period of early synaptogenesis (Luikart et al. 2005). In more stable or mature glutamatergic synapses, BDNF/TrkB signaling may be restricted to regulation of functional and morphological synapse/spine plasticity. TrkB may regulate synapse number in early development by stimulating filopodial motility (Luikart et al. 2008)a process requiring $\operatorname{TrkB}$ kinase activity and PI3-kinase signaling (but not ERK signaling) (Fig. 3A). Therefore, BDNF/TrkB signaling appears to increase synapse number by increasing the probability that a dendritic filopodium will encounter a nearby axon. Interestingly, longterm incubation (24-48 h) of young hippocampal slice cultures with exogenous BDNF also increases spine synapse number (Tyler and Pozzo-Miller 2001), but this did require ERK signaling (Alonso et al. 2004).

Other than the involvement of PI3-kinase, the precise mechanisms that link the BDNFactivated TrkB receptor to $\mathrm{F}$-actin remodeling in filopodial motility or synapse/spine formation remain unclear. Two Dbl family guanine nucleotide exchange factors (GEFs), which regulate Rho family GTPases and actin cytoskeletal dynamics, Vav2 and Tiam1, are activated by 

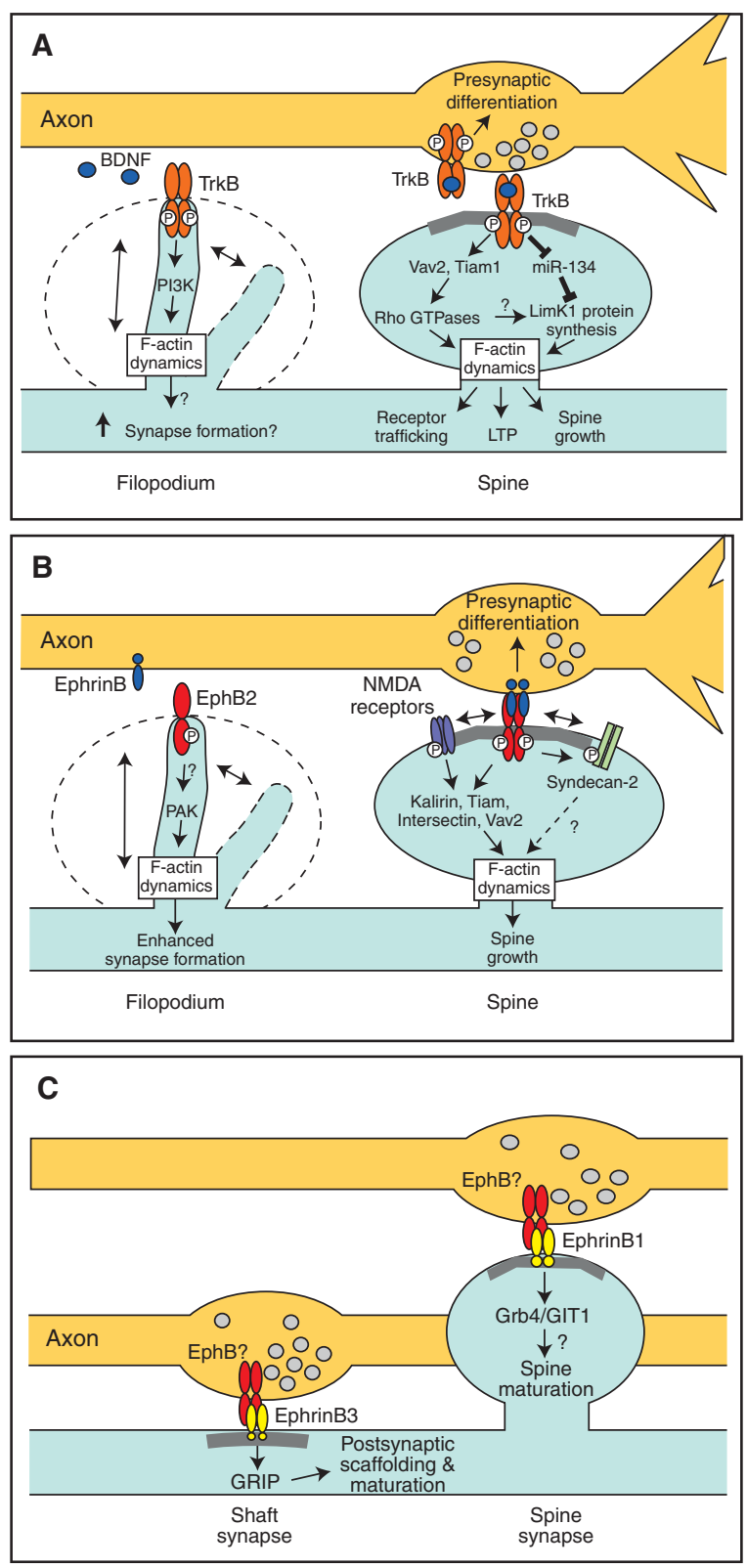

Figure 3. Guidance molecules involved in synapse formation and axon branching. (A) Model for EphB2 receptor functions and signaling in synaptogenesis. $(B)$ Model for BDNF/TrkB receptor functions and signaling in synaptogenesis. (C) Role of ephrinBs in shaft and spine synapse formation.

$\mathrm{BDNF} /$ TrkB signaling. Vav2 is activated by and interacts with $\operatorname{TrkB}$ receptors, and is critical for BDNF-induced generation of Rac-GTP in cortical and hippocampal neurons (C. Hale and C. Cowan, unpubl.). Tiam1 can also be activated by BDNF/TrkB signaling (Miyamoto et al. 2006), which suggests that multiple Rho family GEFs may link BDNF/TrkB receptor signaling to actin cytoskeletal dynamics in neurons. 


\section{EphB2}

Similar to $\operatorname{TrkB}$, the axon guidance receptor, EphB2, plays a key role in normal hippocampal synapse formation (Dalva et al. 2000; Henkemeyer et al. 2003; Kayser et al. 2006; Kayser et al. 2008) (Fig. 3B). EphB2 appears to participate in several aspects of synapse formation, including filopodial motility. EphB2-deficient hippocampal neurons in culture have dramatically reduced filopodial motility and synapse density. EphB2 forward signaling was required for the filopodial motility, but artificially increasing dendritic filopodial motility alone did not rescue the deficit in synapse formation in EphB2-deficient neurons, indicating a key role for the EphB2 extracellular domain in synaptogenesis (Kayser et al. 2008). These observations suggest that EphB2 kinase-dependent filopodial motility functions to increase the frequency of axo-dendritic contacts, whereas the ephrinB/EphB interaction at the surface may stabilize the axo-dendritic contact sites through a cell-cell adhesion mechanism. Alternatively, the EphB2 extracellular domain, which has been shown to recruit NMDA receptors to nascent synapses in culture, may facilitate synapse formation/maturation via a cis postsynaptic mechanism (Dalva et al. 2000). Taken together with the BDNF/TrkB studies, these findings suggest that filopodial motility is part of a complex synaptogenic process that facilitates proper synapse density.

\section{Contact Stabilization}

The ability of a transient axo-dendritic contact to mature into a functional synapse requires stabilization of the cell-cell interaction (Fig. 1B). For the most part, this process is poorly understood. Recent imaging studies of hippocampal pyramidal neurons revealed that dendritic filopodia make repeated, transient contacts with axons, but only some of these contacts become stabilized (Lohmann and Bonhoeffer 2008). The stable contacts were accompanied by dendritic filopodial calcium transients, but these transients did not require glutamate receptors. Although molecular mechanisms that control axo-dendritic contact stabilization are unknown, several high-affinity interactions between cell-surface expressed proteins, such as ephrinB/EphB, Cadherins, SynCaM, and neurexin/neuroligin, are known to regulate synapses. EphB2 represents a good candidate for a contact stabilizing protein, because it requires an extracellular domain function for proper synapse density (Kayser et al. 2008). Another group of proteins implicated in axon guidance and synapse formation is the Cadherin superfamily of proteins. Recently, an RNA interference (RNAi) screen for neuronal genes involved in synapse formation identified two Cadherins, Cadherin 11 and Cadherin 13, as proteins required for proper glutamatergic and GABAergic synapse density (Paradis et al. 2007). Although the precise role(s) of these proteins in synaptogenesis was not determined, they likely stabilize transient axo-dendritic contacts via cell-cell adhesion or facilitate the clustering of synaptic proteins. Similarly, NCadherin regulates the maturation of dendritic spines and excitatory synapses in part through stabilization of dendrite filopodia and spines (Togashi et al. 2002; Abe et al. 2004). Interestingly, Kalirin-7, a Rac-GEF that is highly expressed in dendritic spines and is also implicated in EphB- and NMDA/AMPA receptormediated spine maturation (Penzes et al. 2003; Xie et al. 2007), appears to function downstream of $\mathrm{N}$-Cadherin to promote spine enlargement and maturation (Xie et al. 2007). However, Kalirin-7 is only expressed during the later stages ( $>3$ wk postnatal) of hippocampal and cortical synaptogenesis, which explains why Kalirin $\mathrm{KO}$ mice have reduced cortical dendritic spine density in mature, but not juvenile, mice (Cahill et al. 2009). These findings also suggest that Kalirin isoforms regulate cortical dendritic spine/synapse maintenance rather than synapse formation, although it is difficult to separate these processes in the steady-state environment of the brain.

\section{Synaptic Maturation}

Once a stable contact has been formed, synaptic machinery must be recruited to the site of 
the nascent synapse (Yuste and Bonhoeffer 2004; Tada and Sheng 2006), including postsynaptic recruitment of ion channels, scaffolding proteins, signaling proteins, and components such as protein translational machinery. On the presynaptic membrane, recruitment of synaptic vesicles, ion channels, transmembrane receptors, vesicle docking proteins, mitochondria, etc., must occur at the site of the developing functional synapse. In some cases, the presynaptic specializations form before the axodendritic contact and anchor a location where appropriate synaptogenesis must occur. Axon guidance molecules are clearly involved in the functional and morphological maturation of synapses.

\section{Ephrins and Ephs}

An important early study found that addition of soluble ephrinB to immature neuronal cultures induced the formation of $\mathrm{EphB} / \mathrm{NMDA}$ receptor coclusters on dendrites, and increased the number of functional synapses. The EphBNMDA receptor interaction required the extracellular domains of EphB2 and NR subunits, suggesting a molecular mechanism by which ephrinB/EphB binding facilitates synapse maturation through direct recruitment of NMDA receptors to the site of a forming synapse (Dalva et al. 2000). Activation of EphB2 was also found to induce Src kinase-dependent phosphorylation of NMDA receptors, which in turn increased NMDA receptor calcium permeability (Takasu et al. 2002). Triple and double mutant mice lacking EphB1, EphB2, and EphB3 showed significant deficits in dendritic spine formation and clustering of AMPA and NMDA receptors, consistent with a cell-autonomous, forward signaling role for EphB receptors in dendritic spine formation and synapse maturation (Henkemeyer et al. 2003). Also, addition of soluble ephrinB ligands to mature dissociated hippocampal neurons induced a rapid formation of dendritic spines, which was dependent on the Rac GEF, Kalirin-7 (Penzes et al. 2003). Similar roles for the Rac GEFs, Tiam1 and Intersectin, in EphB2mediated dendritic spine and synapse maturation were also described (Irie and Yamaguchi
2002; Tolias et al. 2007), suggesting that there are multiple mechanisms by which activated EphB receptors stimulate F-actin dynamics during dendritic spine growth and synapse formation. In addition, EphB2 binds and activates Vav2 in cultured neurons (Cowan et al. 2005), and Vav2 is enriched in developing synapses (C. Hale and C. Cowan, unpubl.), indicating that multiple Rho GEFs likely contribute to dendritic spine growth and dynamics.

Using a dominant-negative approach in cultured hippocampal neurons, ephrinB1 reverse signaling in dendrites was shown to contribute to mushroom-type spine formation via a signaling mechanism involving the adaptor protein, Grb4, and the G protein-coupled receptor kinase-interacting protein 1 (GIT1) (Segura et al. 2007). Taken together with findings that ephrinB3 functions postsynaptically to regulate shaft synapse formation (Aoto et al. 2007), these findings suggest that in some contexts, ephrinB reverse signaling in the dendrite can regulate postsynaptic development (Fig. 3C).

In addition to postsynaptic roles in synapse maturation, the ephrinB/EphB interactions appear to contribute to presynaptic development (Fig. 3B). EphrinB1 was shown to be enriched in presynaptic axon terminals in the developing Xenopus retinotectal system, and activation of ephrinB1 reverse signaling by incubation with the soluble extracellular domain of EphB2 increased synapse number, basal synaptic transmission, the AMPAR/NMDAR ratio, and activityinduced LTP (Lim et al. 2008), likely because of accelerated presynaptic maturation.

Taken together, these findings suggest critical roles for ephrins and Ephs during synapse maturation. EphBs appear to promote synapse formation through both extracellular and intracellular mechanisms by regulating cell-cell adhesion, activation of F-actin remodeling, recruiting synaptic proteins to the nascent synapse, and activating ephrinB reverse signaling.

\section{Wnts}

Wnt signaling has been shown to be important for various aspects of neuronal development and plasticity in the nervous system. In 
mammalian cerebellar development, Wnt-7a was shown to play an important role in presynaptic maturation (Hall et al. 2000). Wnt-7a mutant mice had significant delays in presynaptic mossy fiber morphological maturation and clustering of the presynaptic protein, synapsin I (Hall et al. 2000). Synapsins are abundant synaptic vesicle proteins that play important modulatory roles in synaptogenesis and synaptic transmission. The cerebellar findings are consistent with a recent report that Wnt-7a stimulates presynaptic protein clustering and facilitates presynaptic neurotransmitter release probability in CA3-CA1 hippocampal synapses (Cerpa et al. 2008). In addition, Wnts may also play roles in postsynaptic mechanism of synaptogenesis and plasticity. A recent study reported that Wnt-5a induced clustering of PSD-95 in dendritic spines through a JNK-dependent signaling pathway, and Wnt-5a also modulated glutamatergic synaptic transmission through a postsynaptic mechanism (Farias et al. 2009).

\section{Guidance Molecules in General Synaptogenesis}

\section{Semaphorins}

Semaphorins are a large family of secreted or membrane molecules that play diverse roles in axon guidance (Tran et al. 2007). However, several recent studies indicate an additional role for Semaphorins in synapse formation and stability. An RNAi-based screen for proteins involved in hippocampal synapse formation identified two class-4 Semaphorins as regulators of synaptogenesis. RNAi-mediated reduction of Sema4B significantly decreased both glutamatergic and GABAergic synapse number in cultured neurons, whereas reduction of Sema4D, a close family member, was found to selectively decrease GABAergic synapse density (Paradis et al. 2007). These observations revealed that there are both common and synapse subtype-specific factors that regulate synaptogenesis. Semaphorin $5 \mathrm{~B}$ also appears to negatively regulate synapse density because overexpression of Sema5B or addition of exogenous Sema5B reduced synapse density, whereas RNAi-mediated reduction of
Sema5B increased synapse density (O'Connor et al. 2009). The receptor(s) that mediates the Sema5B synapse effect is unknown, but it is interesting to note that Sema5B-induced growth cone repulsion is mediated by a $\mathrm{Ca}^{2+}$-dependent mechanism (To et al. 2007).

Class 3 semaphorins bind to the neuropilin and plexin coreceptors to promote axonal repulsion or attraction (Tran et al. 2007). Interestingly, Neuropilins are found in synaptic compartments of hippocampal neurons. Neuropilin-2 null mice have an increased dendritic spine density on CA1 neurons, although this phenotype was accompanied by a reduced dendritic arbor complexity and length (Gant et al. 2009). Similarly, mice with null mutations for Sema3F, or its coreceptors Neuropilin-2 and Plexin A3, have increased spine sizes and densities in dentate gyrus and cortical pyramidal neurons in apical, but not basal, dendrites (Tran et al. 2009).

\section{Guidance Molecules in Synapse Plasticity}

Functional synapse plasticity is generally defined as a process by which the strength of a synapse is changed, and as a likely mechanism for long-term memory and behavioral plasticity, it represents a major area of current neuroscience research. Recent findings suggest a potential causal relationship between morphological dendritic spine plasticity and functional synapse plasticity. In the mammalian brain, established dendritic spines were once thought be fairly static and stable structures. However, the development of time-lapse in vitro and in vivo imaging techniques has allowed for a more careful analysis of CNS dendritic spine dynamics. In general, established dendritic spines continue to change shape and size over time (Dunaevsky et al. 1999; Trachtenberg et al. 2002; Honkura et al. 2008); however, the magnitude of the changes appears to be smaller in mature neurons than younger ones, and larger dendritic spines are less dynamic than smaller spines (Yasumatsu et al. 2008).

As dendritic spines are rich in F-actin, it is not surprising that intrinsic and extrinsic regulation of F-actin assembly, branching, and 
disassembly control spine dynamics. Fluctuations in spine size/shape in slice cultures appear to be mediated by both synaptic activity-dependent and -independent mechanisms (Yasumatsu et al. 2008). The activity-independent fluctuations are likely because of cell intrinsic properties and may reflect the "noise" of basal actin cytoskeleton remodeling and basal activity of actin remodeling proteins in the spine, perhaps similar to the dynamic changes observed in the constantly changing growth cone morphology during basal axon outgrowth. The importance of basal dendritic spine "morphing" to synaptic and neural circuit function is unclear. In contrast, synaptic activity-induced spine enlargement is correlated with long-term synaptic potentiation (LTP), and vice versa for spine head shrinking and induction of longterm depression (LTD) (Matsuzaki et al. 2004; Okamoto et al. 2004; Honkura et al. 2008; Tanaka et al. 2008). Indeed, pharmacological inhibition of F-actin polymerization blocks the late phase of LTP, but not the early phase (Kim and Lisman 1999; Krucker et al. 2000; Fukazawa et al. 2003; Rex et al. 2007), suggesting that F-actin remodeling is critical for stabilizing the activity-induced changes that underlie potentiation (e.g., insertion of surface AMPA receptors at the synapse and expansion of the PSD). The molecular and cellular mechanisms by which F-actin polymerization stabilizes functional synapse plasticity are not clear, but genes involved in growth cone F-actin dynamics are good candidates for mediating dendritic spine plasticity (Fig. 4).

\section{$B D N F / T r k B$}

$\mathrm{BDNF} /$ TrkB signaling has been linked to functional synapse plasticity in numerous studies (Fig. 4). Recent findings indicate that F-actin remodeling and dendritic spine growth may underlie the BDNF/TrkB effects on long-lasting LTP. Genetic or functional interference with BDNF or TrkB results in LTP deficits (Korte et al. 1995; Patterson et al. 1996; Minichiello et al. 1999; Pozzo-Miller et al. 1999; Kossel et al. 2001; Rex et al. 2007). Consistent with these observations, addition of exogenous BDNF to wild-type hippocampal neurons increases tetanus-induced LTP in a Trk kinasedependent manner (Figurov et al. 1996; Rex et al. 2007), and this effect correlates with an increase in spine F-actin content (Rex et al.

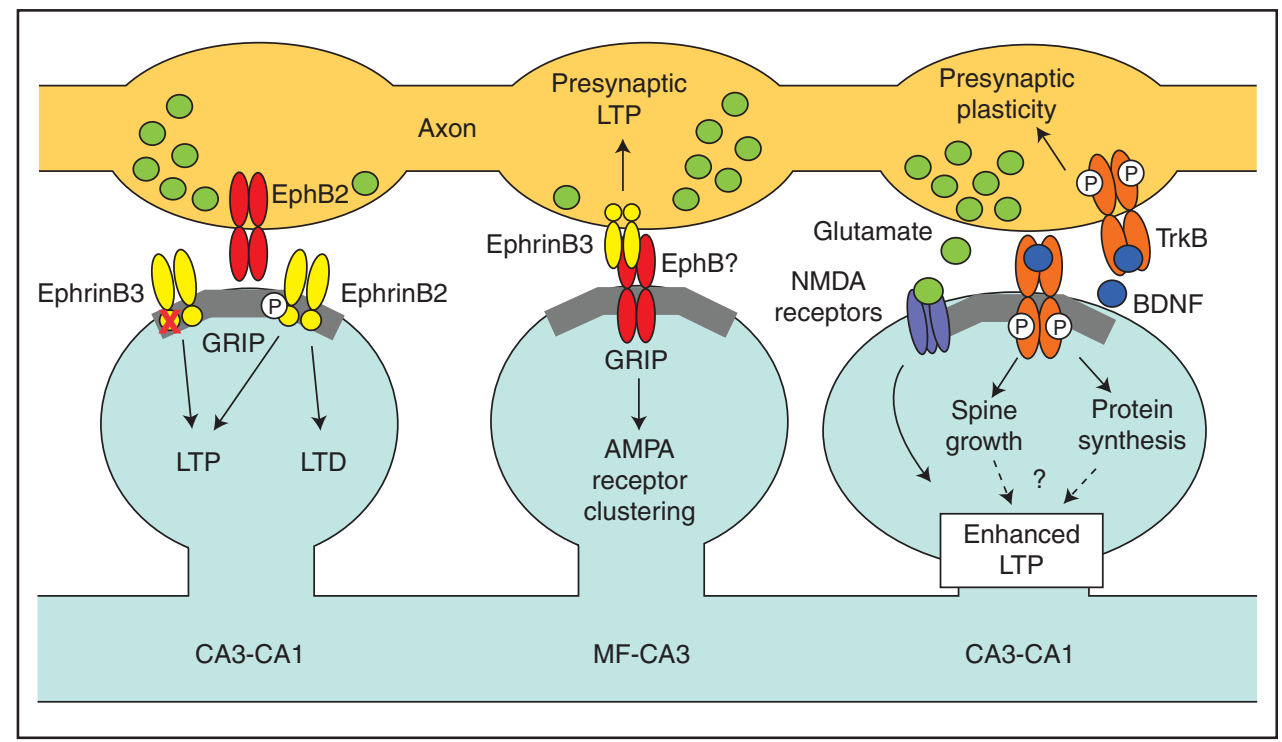

Figure 4. Model for ephrinB, EphB, and BDNF/TrkB signaling in structural and functional synapse plasticity in the hippocampus. 
2007). Also, a long-lasting form of dendritic spine enlargement, which was induced by local glutamate uncaging combined with postsynaptic spikes (spike-timing protocol), was dependent on BDNF/TrkB signaling (Tanaka et al. 2008). Addition of glutamate to a dendritic spine is sufficient to induce transient spine head enlargement (Matsuzaki et al. 2004; Tanaka et al. 2008) in a NMDA receptor-dependent manner, but endogenous BDNF/TrkB signaling appears to stabilize the spine enlargement. Together, these findings suggest that stimulusinduced BDNF release and TrkB signaling may stabilize dendritic spine growth and LTP via an F-actin-dependent process.

Although the effects of BDNF on dendritic spine morphology/density and LTP are well established, the downstream signaling mechanisms by which TrkB mediates these effects are less clear. Several studies have reported that the BDNF-induced effects on spine and synapse plasticity require new protein synthesis. A recent study (Schratt et al. 2006) revealed that a microRNA, miR-134, is located in dendrites and spines and suppresses local translation of Lim kinase ( LimK), a F-actin-regulating protein that is activated by Rac/Cdc42 family GTPases (via PAK). BDNF appears to block miR-134's translational repressor function, which allows for local synaptic translation of LimK to facilitate dendrite spine growth. Consistent with this idea, LimKdeficient mice have smaller synapses and spines lacking actin (Meng et al. 2002).

Rho-family GTPases have been implicated in spine growth and maturation (Tashiro and Yuste 2004). As such, BDNF likely controls spine plasticity by regulating Rho family GTPases. We recently found that BDNF/TrkB activates Vav2, a Rho/Rac family GEF that is highly expressed in the developing brain and synapses. Vav GEFs are required for BDNF-induced Rac-GTP activation and CA1 dendritic spine growth (C. Hale, K. Dietz, and C. Cowan, unpubl.), revealing an important role for Vav GEFs in BDNF-dependent spine growth and synapse plasticity. Similarly, Tiam1 mediates BDNF-induced Rac-GTP formation and BDNF-induced chemotaxis in the developing cerebellum (Zhou et al. 2007b), and Tiam1 also appears to mediate BDNF-induced neurite outgrowth in cultured cortical neurons (Miyamoto et al. 2006), suggesting that BDNF-induced F-actin dynamics may be mediated by different or multiple Rho GEFs, depending on the neuronal population, development stage, and subcellular structure.

In addition to a postsynaptic role for BDNF/ TrkB signaling during induction/maintenance of LTP or dendritic spine growth, BDNF has also been reported to alter presynaptic functions, such as regulation of synaptic vesicle release probability (Tyler and Pozzo-Miller 2001) (Fig. 4). Similarly, mice lacking presynaptic TrkB in the CA3 hippocampal neurons have structural and electrophysiological presynaptic defects consistent with TrkB playing an essential presynaptic role in development and plasticity (Luikart et al. 2005).

\section{Ephrins and Ephs}

In addition to a clear role in modulating synapse formation during early hippocampal development, ephrins and Ephs have also been reported to regulate morphological spine plasticity and LTP (Fig. 4). EphrinB2 knockout mice have severe deficits in both LTP and LTD (Grunwald et al. 2004; Bouzioukh et al. 2007). Phosphorylation of five ephrinB2 intracellular domain tyrosines is required for normal CA3-CA1 hippocampal LTP, but not for LTD, whereas the PDZ-binding site on the carboxyl terminus of ephrinB2 is required for both LTP and LTD (Bouzioukh et al. 2007). The molecular mechanisms are not clear; however, ephrinB2 appears to regulate AMPA receptor trafficking and stabilization of surface AMPAR expression through recruitment of the glutamate receptor-interacting proteins (GRIP1 and GRIP2) (Essmann et al. 2008).

Similar to ephrinB2, mice lacking ephrinB3 have deficits in CA3-CA1 LTP (Grunwald et al. 2004; Rodenas-Ruano et al. 2006); however, no deficit was observed in another study (Armstrong et al. 2006). Interestingly, ephrinB3-mediated LTP does not require its intracellular domain (i.e., reverse signaling) for CA3CA1 LTP (Rodenas-Ruano et al. 2006). In contrast, mossy fiber-CA3 LTP, which involves a 
presynaptic ephrinB3 function, does require ephrinB3 reverse signaling (Armstrong et al. 2006). Interestingly, ephrinB1 in the developing Xenopus retinotectal synapses appears to regulate neurotransmitter release and postsynaptic development and function via a presynaptic mechanism (Lim et al. 2008).

Ephs also contribute to functional and morphological synapse plasticity. In EphB2 null mice, CA3-CA1 LTP is reduced (Henderson et al. 2001), but no LTP defects are observed in EphB2 knock-in mice lacking its intracellular region (Henkemeyer et al. 1996). This suggests that EphB2 functions presynaptically as the ligand for ephrinBs (postsynaptic), which are required for normal LTP (see previous), or that EphB2 might function on the postsynaptic neurons through an extracellular domain-dependent process, or both. The former idea is the most straightforward considering the phenotypes of ephrinB2/3 null mice, but the extracellular domain of EphB2 mediates an interaction with NMDA receptors (Dalva et al. 2000) and NMDA receptors are required for LTP. Therefore, future studies with selective knockout ofEphB2 in CA3 versus CA1 neurons will be helpful to address this issue. Note that the kinase-independent role of EphB2 for LTP is in contrast to its kinasedependent role in spine formation, filopodial motility, and synapse formation, suggesting that once synapses are formed, EphB2 functions in a non-cell autonomous fashion to regulate synaptic plasticity.

The situation in the mossy fiber-CA3 LTP is more complex than CA3-CA1 LTP. In this case, postsynaptic EphB receptors appear to facilitate LTP via a PDZ domain-dependent interaction with GRIPs, which cluster AMPA receptors, and by acting as a ligand for presynaptic ephrinBs (Contractor et al. 2002). Activation of ephrinB reverse signaling with soluble EphB2Fc increased basal synaptic transmission, and this occluded tetanus-induced LTP, suggesting that enhancements of presynaptic function facilitate mossy fiber-CA3 LTP. Unfortunately, developmental defects in CA3 region in the EphB2 null mice precluded a more definitive analysis of the CA3 EphBs involved in this process.
EphA receptors and ephrinAs have also been implicated in synaptic plasticity. Hippocampal perfusion of a soluble EphA5-Fc fusion protein reduced tetanus-induced LTP, possibly by blocking EphA forward signaling, whereas incubation with ephrinA5-Fc partially mimicked LTP (Gao et al. 1998). In addition, mice lacking EphA4 show kinase-independent deficits in CA3-CA1 LTP (Grunwald et al. 2004), and CA1-specific EphA4 knockout mice have CA3CA1 LTP deficits (Filosa et al. 2009). In this case, CA1-expressed EphA4 appears to activate ephrinA3 reverse signaling in astrocytes, which in turn regulates glial glutamate transporter levels. Consistently, ephrinA3 null mice also have CA3-CA1 LTP deficits (Filosa et al. 2009). In contrast, EphA4 appears to contribute to dendritic spine retraction in an Eph kinasedependent manner (Murai et al. 2003; Bourgin et al. 2007; Richter et al. 2007; Zhou et al. 2007a; Carmona et al. 2009). This process may be mediated by a Cdk5-dependent phosphorylation of Ephexin 1 and activation of RhoA (Fu et al. 2007 ) and/or by inhibition of $\beta 1$-Integrin signaling that control spine stability through interactions with the extracellular matrix (Bourgin et al. 2007). EphA4 in dendritic spines appears to be activated by glial cell-expressed ephrinA3, and mouse knockouts of either of these genes have dendritic spine abnormalities (Murai et al. 2003; Carmona et al. 2009). However, the relevance of the ephrinA3/EphA4 regulation of spine morphology for functional synapse plasticity is not yet clear.

\section{Nogo Recepter}

Nogo ligand and Nogo Receptors were originally described for their function in blocking axon outgrowth after spinal cord injury; however, recent reports indicate that Nogo Receptor 1 (NgR1) is also involved in hippocampal synapse plasticity (Lee et al. 2008). Specifically, mice lacking NgR1 had attenuated CA3-CA1 LTD, while expressing normal LTP. However, the molecular mechanism by which NgR1 regulates LTD is unknown, but may involve modulation of co-receptors, like the FGF receptors (Lee et al. 2008). 


\section{Semaphorins and Plexins}

Class 3 semaphorins (Sema3A-3F) function as soluble, secreted ligands that bind and activate the co-receptor complexes that contain plexins and neuropilins (de Wit and Verhaagen 2003). These ligands and receptors are not only expressed in the developing brain, but are also expressed in the adult brain. Neuropilin1 and 2 are both found in the synapse (Sahay et al. 2005; Bouzioukh et al. 2006), and recombinant Sema3A and Sema3F bind throughout the juvenile and adult hippocampus. Addition of soluble Sema3F increased synaptic responses from both CA1 pyramidal and dentate gyrus granule neurons through a postsynaptic mechanism(s) (Sahay et al. 2005). Sema3F null mice were found to be prone to seizures, but it is difficult to know if this phenotype is related to the observed effects on synaptic transmission. In contrast to the effects of Sema3F, acute application of soluble Sema3A induced rapid, synaptic depression in adult CA1 hippocampal neurons that was reversed on Sema3A washout (Bouzioukh et al. 2006). Interestingly, mRNA levels of some semaphorins and neuropilins are regulated by experience and activity (Shimakawa et al. 2002; Barnes et al. 2003; Holtmaat et al. 2003; O’Donnell et al. 2003), suggesting that regulation of these ligand/receptor genes may play a role in synapse plasticity. A key downstream target of Sema3A/Npn1/PlexinA signaling in axon guidance is the collapsin response mediator protein (CRMP), which binds to tubulin dimers and regulates microtubule assembly (Fukata et al. 2002). Interestingly, CRMP1 null mice had reduced CA3-CA1 LTP and deficits in spatial memory (Su et al. 2007), suggesting the interesting possibility that CRMPdependent regulation of microtubules may be critical for synapse plasticity.

\section{Wnts}

Wnt signaling has been shown to modulate both presynaptic and postsynaptic functions, such that Wnt-7a can increase presynaptic CA3-CA1 hippocampal vesicle release probability (Cerpa et al. 2008) and Wnt-5a appears to modulate synaptic transmission through a postsynaptic mechanism possibly involving PSD-95 clustering in dendritic spines (Farias et al. 2009). Wnt signaling appears to play an important role in experience-dependent changes in synaptic connectivity in the hippocampus in vivo. Mice exposed to an enriched environment showed increased MF-CA3 spine and synapse numbers, which involved postsynaptic expression of Wnt-7a/b in CA3 hippocampal neurons (Gogolla et al. 2009). Taken together, these studies suggest that Wnt signaling will emerge as a critical regulator of synapse function in vertebrates.

\section{Synaptic Scaling}

The TGF- $\beta$ family of secreted proteins serves as morphogens that play diverse functions in developmental biology. The TGF- $\beta$ family members, BMP7 (Augsburger et al. 1999; Butler and Dodd 2003) and UNC-129 (Colavita et al. 1998), act as instructive cues for axon guidance. However, TGF- $\beta$ family genes also appear to mediate synaptic scaling during development, a process whereby the nervous system expands to accommodate the growth of body size. At Drosophila neuromuscular junctions, loss-offunction mutants of the BMP7 homolog, gbb, or its receptor wit, Thv, and Sax, or downstream signaling molecules Mad and Medea, display decreased number of synapses, ultrastructural defects, and severely compromised synaptic transmission during the larval growth stage (Marques 2005). Gbb is expressed in the postsynaptic muscles, whereas the receptors and signaling components are required in the axon (McCabe et al. 2003). Hence, Gbb can potentially act as a retrograde signal to stimulate the growth of NMJs. One study indicates that diminished presynaptic glutamate release or insufficient $\mathrm{Ca}^{2+}$ entry in the muscle cells leads to reduced activity of CaMKII in the muscle, which then triggers the release of the Gbb. In turn, Gbb acts through the presynaptic Wit receptor to activate the compensatory growth program (Haghighi et al. 2003). Therefore, Gbb is the output of a feedback loop to coordinate the growth of the muscle and the presynaptic 
terminals to ensure sufficient depolarization during development.

\section{SUMMARY AND CONCLUSIONS}

Overwhelming evidence suggest that many molecules that were initially discovered for their functions in axon guidance also play important functions in synapse formation. The reuse of molecules in different developmental processes is not a new concept. For example, many morphogens such as Wnts and Hedgehogs are critical for cell fate induction at early developmental stages. However, they also play important roles in later events including axon guidance. Whereas there are many examples of molecules involved in both axon guidance and synapse formation, the existing literature offers very little insight regarding how diverse cellular events can be regulated by the same membrane receptors. Future research on the downstream components of these receptor pathways in both axon guidance and synapse formation will shed light on how they are mechanistically linked.

\section{REFERENCES}

Abe K, Chisaka O, Van Roy F, Takeichi M. 2004. Stability of dendritic spines and synaptic contacts is controlled by $\alpha$ N-catenin. Nat Neurosci 7: 357-363.

Alonso M, Medina JH, Pozzo-Miller L. 2004. ERK1/2 activation is necessary for BDNF to increase dendritic spine density in hippocampal CA1 pyramidal neurons. Learn Mem 11: 172-178.

Aoto J, Ting P, Maghsoodi B, Xu N, Henkemeyer M, Chen L. 2007. Postsynaptic ephrinB3 promotes shaft glutamatergic synapse formation. J Neurosci 27: 7508-7519.

Armstrong JN, Saganich MJ, Xu NJ, Henkemeyer M, Heinemann SF, Contractor A. 2006. B-ephrin reverse signaling is required for NMDA-independent long-term potentiation of mossy fibers in the hippocampus. J Neurosci 26: 3474-3481.

Augsburger A, Schuchardt A, Hoskins S, Dodd J, Butler S. 1999. BMPs as mediators of roof plate repulsion of commissural neurons. Neuron 24: 127-141.

Barnes G, Puranam RS, Luo Y, McNamara JO. 2003. Temporal specific patterns of semaphorin gene expression in rat brain after kainic acid-induced status epilepticus. Hippocampus 13: 1-20.

Bourgin C, Murai KK, Richter M, Pasquale EB. 2007. The EphA4 receptor regulates dendritic spine remodeling by affecting $\beta 1$-integrin signaling pathways. J Cell Biol 178: 1295-1307.
Bouzioukh F, Daoudal G, Falk J, Debanne D, Rougon G, Castellani V. 2006. Semaphorin3A regulates synaptic function of differentiated hippocampal neurons. Eur $J$ Neurosci 23: 2247-2254.

Bouzioukh F, Wilkinson GA, Adelmann G, Frotscher M, Stein V, Klein R. 2007. Tyrosine phosphorylation sites in ephrinB2 are required for hippocampal long-term potentiation but not long-term depression. J Neurosci 27: $11279-11288$.

Butler SJ, Dodd J. 2003. A role for BMP heterodimers in roof plate-mediated repulsion of commissural axons. Neuron 38: 389-401.

Cahill ME, Xie Z, Day M, Barbolina MV, Miller CA, Weiss C, Radulovic J, Sweatt JD, Disterhoft JF, Surmeier DJ, et al. 2009. Kalirin regulates cortical spine morphogenesis and disease-related behavioral phenotypes. Proc Natl Acad Sci 106: 13058-13063.

Carmona MA, Murai KK, Wang L, Roberts AJ, Pasquale EB. 2009. Glial ephrin-A3 regulates hippocampal dendritic spine morphology and glutamate transport. Proc Natl Acad Sci 106: $12524-12529$.

Cerpa W, Godoy JA, Alfaro I, Farias GG, Metcalfe MJ, Fuentealba R, Bonansco C, Inestrosa NC. 2008. Wnt-7a modulates the synaptic vesicle cycle and synaptic transmission in hippocampal neurons. J Biol Chem 283: 5918-5927.

Chao DL, Ma L, Shen K. 2009. Transient cell-cell interactions in neural circuit formation. Nat Rev Neurosci 10: $262-271$.

Colavita A, Krishna S, Zheng H, Padgett RW, Culotti JG. 1998. Pioneer axon guidance by UNC-129, a C. elegans TGF- $\beta$. Science 281: 706-709.

Colon-Ramos DA, Margeta MA, Shen K. 2007. Glia promote local synaptogenesis through UNC-6 (netrin) signaling in C. elegans. Science 318: 103-106.

Contractor A, Rogers C, Maron C, Henkemeyer M, Swanson GT, Heinemann SF. 2002. Trans-synaptic Eph receptorephrin signaling in hippocampal mossy fiber LTP. Science 296: $1864-1869$.

Cowan CW, Shao YR, Sahin M, Shamah SM, Lin MZ, Greer PL, Gao S, Griffith EC, Brugge JS, Greenberg ME. 2005 Vav family GEFs link activated Ephs to endocytosis and axon guidance. Neuron 46: 205-217.

Dalva MB, Takasu MA, Lin MZ, Shamah SM, Hu L, Gale NW, Greenberg ME. 2000. EphB receptors interact with NMDA receptors and regulate excitatory synapse formation. Cell 103: 945-956.

de Wit J, Verhaagen J. 2003. Role of semaphorins in the adult nervous system. Prog Neurobiol 71: 249-267.

Dunaevsky A, Tashiro A, Majewska A, Mason C, Yuste R. 1999. Developmental regulation of spine motility in the mammalian central nervous system. Proc Natl Acad Sci 96: $13438-13443$.

Essmann CL, Martinez E, Geiger JC, Zimmer M, Traut MH, Stein V, Klein R, Acker-Palmer A. 2008. Serine phosphorylation of ephrinB2 regulates trafficking of synaptic AMPA receptors. Nat Neurosci 11: 1035-1043.

Farias GG, Alfaro IE, Cerpa W, Grabowski CP, Godoy JA, Bonansco C, Inestrosa NC. 2009. Wnt-5a/JNK signaling promotes the clustering of PSD-95 in hippocampal neurons. J Biol Chem 284: 15857-15866. 
Fiala JC, Feinberg M, Popov V, Harris KM. 1998. Synaptogenesis via dendritic filopodia in developing hippocampal area CA1. J Neurosci 18: 8900-8911.

Figurov A, Pozzo-Miller LD, Olafsson P, Wang T, Lu B. 1996. Regulation of synaptic responses to high-frequency stimulation and LTP by neurotrophins in the hippocampus. Nature 381: 706-709.

Filosa A, Paixao S, Honsek SD, Carmona MA, Becker L, Feddersen B, Gaitanos L, Rudhard Y, Schoepfer R, Klopstock T, et al. 2009. Neuron-glia communication via EphA4/ ephrin-A3 modulates LTP through glial glutamate transport. Nat Neurosci 12: 1285-1292.

Fu WY, Chen Y, Sahin M, Zhao XS, Shi L, Bikoff JB, Lai KO, Yung WH, Fu AK, Greenberg ME, et al. 2007. Cdk5 regulates EphA4-mediated dendritic spine retraction through an ephexin1-dependent mechanism. Nat Neurosci 10: 67-76.

Fukata Y, Itoh TJ, Kimura T, Menager C, Nishimura T, Shiromizu T, Watanabe $\mathrm{H}$, Inagaki $\mathrm{N}$, Iwamatsu $\mathrm{A}, \mathrm{Hotani} \mathrm{H}$, et al. 2002. CRMP-2 binds to tubulin heterodimers to promote microtubule assembly. Nat Cell Biol 4: 583-591.

Fukazawa Y, Saitoh Y, Ozawa F, Ohta Y, Mizuno K, Inokuchi K. 2003. Hippocampal LTP is accompanied by enhanced F-actin content within the dendritic spine that is essential for late LTP maintenance in vivo. Neuron 38: 447-460.

Gant JC, Thibault O, Blalock EM, Yang J, Bachstetter A, Kotick J, Schauwecker PE, Hauser KF, Smith GM, Mervis R, et al. 2009. Decreased number of interneurons and increased seizures in neuropilin 2 deficient mice: implications for autism and epilepsy. Epilepsia 50: 629-645.

Gao WQ, Shinsky N, Armanini MP, Moran P, Zheng JL, Mendoza-Ramirez JL, Phillips HS, Winslow JW, Caras IW. 1998. Regulation of hippocampal synaptic plasticity by the tyrosine kinase receptor, REK7/EphA5, and its ligand, AL-1/Ephrin-A5. Mol Cell Neurosci 11: 247-259.

Gogolla N, Galimberti I, Deguchi Y, Caroni P. 2009. Wnt signaling mediates experience-related regulation of synapse numbers and mossy fiber connectivities in the adult hippocampus. Neuron 62: 510-525.

Goldberg JH, Tamas G, Aronov D, Yuste R. 2003. Calcium microdomains in aspiny dendrites. Neuron 40: 807-821.

Grunwald IC, Korte M, Adelmann G, Plueck A, Kullander K, Adams RH, Frotscher M, Bonhoeffer T, Klein R. 2004. Hippocampal plasticity requires postsynaptic ephrinBs. Nat Neurosci 7: 33-40.

Haghighi AP, McCabe BD, Fetter RD, Palmer JE, Hom S, Goodman CS. 2003. Retrograde control of synaptic transmission by postsynaptic CaMKII at the Drosophila neuromuscular junction. Neuron 39: 255-267.

Hall AC, Lucas FR, Salinas PC. 2000. Axonal remodeling and synaptic differentiation in the cerebellum is regulated by WNT-7a signaling. Cell 100: 525-535.

Hedgecock EM, Culotti JG, Hall DH. 1990. The unc-5, unc-6, and unc- 40 genes guide circumferential migrations of pioneer axons and mesodermal cells on the epidermis in C. elegans. Neuron 4: 61-85.

Henderson JT, Georgiou J, Jia Z, Robertson J, Elowe S, Roder JC, Pawson T. 2001. The receptor tyrosine kinase EphB2 regulates NMDA-dependent synaptic function. Neuron 32: $1041-1056$.
Henkemeyer M, Itkis OS, Ngo M, Hickmott PW, Ethell IM. 2003. Multiple EphB receptor tyrosine kinases shape dendritic spines in the hippocampus. J Cell Biol 163: 1313-1326.

Henkemeyer M, Orioli D, Henderson JT, Saxton TM, Roder J, Pawson T, Klein R. 1996. Nuk controls pathfinding of commissural axons in the mammalian central nervous system. Cell 86: 35-46.

Holtmaat AJ, Gorter JA, De Wit J, Tolner EA, Spijker S, Giger RJ, Lopes da Silva FH, Verhaagen J. 2003. Transient downregulation of Sema3A mRNA in a rat model for temporal lobe epilepsy. A novel molecular event potentially contributing to mossy fiber sprouting. Exp Neurol 182: $142-150$.

Honkura N, Matsuzaki M, Noguchi J, Ellis-Davies GC, Kasai H. 2008. The subspine organization of actin fibers regulates the structure and plasticity of dendritic spines. Neuron 57: 719-729.

Huang EJ, Reichardt LF. 2003. Trk receptors: roles in neuronal signal transduction. Annu Rev Biochem 72: 609-642.

Irie F, Yamaguchi Y. 2002. EphB receptors regulate dendritic spine development via intersectin, Cdc42 and N-WASP. Nat Neurosci 5: 1117-1118.

Kayser MS, McClelland AC, Hughes EG, Dalva MB. 2006. Intracellular and trans-synaptic regulation of glutamatergic synaptogenesis by EphB receptors. J Neurosci 26: 12152-12164.

Kayser MS, Nolt MJ, Dalva MB. 2008. EphB receptors couple dendritic filopodia motility to synapse formation. Neuron 59: 56-69.

Kim CH, Lisman JE. 1999. A role of actin filament in synaptic transmission and long-term potentiation. J Neurosci 19: 4314-4324.

Klassen MP, Shen K. 2007. Wnt signaling positions neuromuscular connectivity by inhibiting synapse formation in C. elegans. Cell 130: 704-716.

Korte M, Carroll P, Wolf E, Brem G, Thoenen H, Bonhoeffer T. 1995. Hippocampal long-term potentiation is impaired in mice lacking brain-derived neurotrophic factor. Proc Natl Acad Sci 92: 8856-8860.

Kossel AH, Cambridge SB, Wagner U, Bonhoeffer T. 2001. A caged $\mathrm{Ab}$ reveals an immediate/instructive effect of BDNF during hippocampal synaptic potentiation. Proc Natl Acad Sci 98: 14702-14707.

Krucker T, Siggins GR, Halpain S. 2000. Dynamic actin filaments are required for stable long-term potentiation (LTP) in area CA1 of the hippocampus. Proc Natl Acad Sci 97: 6856-6861.

Lee H, Raiker SJ, Venkatesh K, Geary R, Robak LA, Zhang Y, Yeh HH, Shrager P, Giger RJ. 2008. Synaptic function for the Nogo-66 receptor NgR1: regulation of dendritic spine morphology and activity-dependent synaptic strength. J Neurosci 28: 2753-2765.

Lim BK, Matsuda N, Poo MM. 2008. Ephrin-B reverse signaling promotes structural and functional synaptic maturation in vivo. Nat Neurosci 11: 160-169.

Lohmann C, Bonhoeffer T. 2008. A role for local calcium signaling in rapid synaptic partner selection by dendritic filopodia. Neuron 59: 253-260. 
Lu Y, Christian K, Lu B. 2008. BDNF: a key regulator for protein synthesis-dependent LTP and long-term memory? Neurobiol Learn Mem 89: 312-323.

Luikart BW, Nef S, Virmani T, Lush ME, Liu Y, Kavalali ET, Parada LF. 2005. TrkB has a cell-autonomous role in the establishment of hippocampal Schaffer collateral synapses. J Neurosci 25: 3774-3786.

Luikart BW, Parada LF. 2006. Receptor tyrosine kinase Bmediated excitatory synaptogenesis. Prog Brain Res 157: $15-24$.

Luikart BW, Zhang W, Wayman GA, Kwon CH, Westbrook GL, Parada LF. 2008. Neurotrophin-dependent dendritic filopodial motility: a convergence on PI3K signaling. $J$ Neurosci 28: 7006-7012.

Marques G. 2005. Morphogens and synaptogenesis in Drosophila. J Neurobiol 64: 417-434.

Matsuzaki M, Honkura N, Ellis-Davies GC, Kasai H. 2004. Structural basis of long-term potentiation in single dendritic spines. Nature 429: 761-766.

McCabe BD, Marques G, Haghighi AP, Fetter RD, Crotty ML, Haerry TE, Goodman CS, O'Connor MB. 2003. The BMP homolog Gbb provides a retrograde signal that regulates synaptic growth at the Drosophila neuromuscular junction. Neuron 39: 241-254.

Meng Y, Zhang Y, Tregoubov V, Janus C, Cruz L, Jackson M, Lu WY, MacDonald JF, Wang JY, Falls DL, et al. 2002. Abnormal spine morphology and enhanced LTP in LIMK-1 knockout mice. Neuron 35: 121-133.

Minichiello L, Korte M, Wolfer D, Kuhn R, Unsicker K, Cestari V, Rossi-Arnaud C, Lipp HP, Bonhoeffer T, Klein R. 1999. Essential role for TrkB receptors in hippocampusmediated learning. Neuron 24: 401-414.

Miyamoto Y, Yamauchi J, Tanoue A, Wu C, Mobley WC. 2006. TrkB binds and tyrosine-phosphorylates Tiam1, leading to activation of Racl and induction of changes in cellular morphology. Proc Natl Acad Sci 103: 10444-10449.

Murai KK, Nguyen LN, Irie F, Yamaguchi Y, Pasquale EB. 2003. Control of hippocampal dendritic spine morphology through ephrin-A3/EphA4 signaling. Nat Neurosci 6: $153-160$.

O'Connor TP, Cockburn K, Wang W, Tapia L, Currie E, Bamji SX. 2009. Semaphorin 5B mediates synapse elimination in hippocampal neurons. Neural Dev 4: 18.

O’Donnell J, Stemmelin J, Nitta A, Brouillette J, Quirion R. 2003. Gene expression profiling following chronic NMDA receptor blockade-induced learning deficits in rats. Synapse 50: 171-180.

Okamoto K, Nagai T, Miyawaki A, Hayashi Y. 2004. Rapid and persistent modulation of actin dynamics regulates postsynaptic reorganization underlying bidirectional plasticity. Nat Neurosci 7: 1104-1112.

Paradis S, Harrar DB, Lin Y, Koon AC, Hauser JL, Griffith EC, Zhu L, Brass LF, Chen C, Greenberg ME. 2007. An RNAi-based approach identifies molecules required for glutamatergic and GABAergic synapse development. Neuron 53: 217-232.

Patterson SL, Abel T, Deuel TA, Martin KC, Rose JC, Kandel ER. 1996. Recombinant BDNF rescues deficits in basal synaptic transmission and hippocampal LTP in BDNF knockout mice. Neuron 16: 1137-1145.
Penzes P, Beeser A, Chernoff J, Schiller MR, Eipper BA, Mains RE, Huganir RL. 2003. Rapid induction of dendritic spine morphogenesis by trans-synaptic ephrinBEphB receptor activation of the Rho-GEF kalirin. Neuron 37: 263-274.

Poon VY, Klassen MP, Shen K. 2008. UNC-6/netrin and its receptor UNC-5 locally exclude presynaptic components from dendrites. Nature 455: 669-673.

Pozzo-Miller LD, Gottschalk W, Zhang L, McDermott K, Du J, Gopalakrishnan R, Oho C, Sheng ZH, Lu B. 1999. Impairments in high-frequency transmission, synaptic vesicle docking, and synaptic protein distribution in the hippocampus of BDNF knockout mice. J Neurosci 19: 4972-4983.

Rex CS, Lin CY, Kramar EA, Chen LY, Gall CM, Lynch G. 2007. Brain-derived neurotrophic factor promotes longterm potentiation-related cytoskeletal changes in adult hippocampus. J Neurosci 27: 3017-3029.

Richter M, Murai KK, Bourgin C, Pak DT, Pasquale EB. 2007. The EphA4 receptor regulates neuronal morphology through SPAR-mediated inactivation of Rap GTPases. J Neurosci 27: 14205-14215.

Rodenas-Ruano A, Perez-Pinzon MA, Green EJ, Henkemeyer M, Liebl DJ. 2006. Distinct roles for ephrinB3 in the formation and function of hippocampal synapses. Dev Biol 292: 34-45.

Sabo SL, Gomes RA, McAllister AK. 2006. Formation of presynaptic terminals at predefined sites along axons. J Neurosci 26: 10813-10825.

Sahay A, Kim CH, Sepkuty JP, Cho E, Huganir RL, Ginty DD, Kolodkin AL. 2005. Secreted semaphorins modulate synaptic transmission in the adult hippocampus. J Neurosci 25: 3613-3620.

Schratt GM, Tuebing F, Nigh EA, Kane CG, Sabatini ME, Kiebler M, Greenberg ME. 2006. A brain-specific microRNA regulates dendritic spine development. Nature 439: 283-289.

Segura I, Essmann CL, Weinges S, Acker-Palmer A. 2007. Grb4 and GIT1 transduce ephrinB reverse signals modulating spine morphogenesis and synapse formation. Nat Neurosci 10: 301-310.

Shimakawa S, Suzuki S, Miyamoto R, Takitani K, Tanaka K, Tanabe T, Wakamiya E, Nakamura F, Kuno M, Matsuura S, et al. 2002. Neuropilin-2 is overexpressed in the rat brain after limbic seizures. Brain Res 956: 67-73.

Soler-Llavina GJ, Sabatini BL. 2006. Synapse-specific plasticity and compartmentalized signaling in cerebellar stellate cells. Nat Neurosci 9: 798-806.

Su KY, Chien WL, Fu WM, Yu IS, Huang HP, Huang PH, Lin SR, Shih JY, Lin YL, Hsueh YP, et al. 2007. Mice deficient in collapsin response mediator protein-1 exhibit impaired long-term potentiation and impaired spatial learning and memory. J Neurosci 27: 2513-2524.

Tada T, Sheng M. 2006. Molecular mechanisms of dendritic spine morphogenesis. Curr Opin Neurobiol 16: 95-101.

Takasu MA, Dalva MB, Zigmond RE, Greenberg ME. 2002. Modulation of NMDA receptor-dependent calcium influx and gene expression through EphB receptors. Science 295: 491-495.

Tanaka J, Horiike Y, Matsuzaki M, Miyazaki T, EllisDavies GC, Kasai H. 2008. Protein synthesis and 
K. Shen and C.W. Cowan

neurotrophin-dependent structural plasticity of single dendritic spines. Science 319: 1683-1687.

Tashiro A, Yuste R. 2004. Regulation of dendritic spine motility and stability by Racl and Rho kinase: evidence for two forms of spine motility. Mol Cell Neurosci 26: 429-440.

To KC, Church J, O'Connor TP. 2007. Combined activation of calpain and calcineurin during ligand-induced growth cone collapse. Mol Cell Neurosci 36: 425-434.

Togashi H, Abe K, Mizoguchi A, Takaoka K, Chisaka O, Takeichi M. 2002. Cadherin regulates dendritic spine morphogenesis. Neuron 35: 77-89.

Tolias KF, Bikoff JB, Kane CG, Tolias CS, Hu L, Greenberg ME. 2007. The Racl guanine nucleotide exchange factor Tiam1 mediates EphB receptor-dependent dendritic spine development. Proc Natl Acad Sci 104: 7265-7270.

Trachtenberg JT, Chen BE, Knott GW, Feng G, Sanes JR, Welker E, Svoboda K. 2002. Long-term in vivo imaging of experience-dependent synaptic plasticity in adult cortex. Nature 420: 788-794.

Tran TS, Kolodkin AL, Bharadwaj R. 2007. Semaphorin regulation of cellular morphology. Annu Rev Cell Dev Biol 23: 263-292.

Trans TS, Rubio ME, Clem RL, Johnson D, Case L, TessierLavigne M, Huganir RL, Ginty DD, Kolodkin AL. 2009. Secreted semaphorins control spine distribution and morphogenesis in the postnatal CNS. Nature PMID 20010807.

Tyler WJ, Pozzo-Miller LD. 2001. BDNF enhances quantal neurotransmitter release and increases the number of docked vesicles at the active zones of hippocampal excitatory synapses. J Neurosci 21: 4249-4258.

White JG, Southgate E, Thomson JN, Brenner S. 1986. The structure of the nervous system of the nematode Caenorhabditis elegans. Philos Trans R Soc Lond B Biol Sci 314: $1-340$.

Xie Z, Srivastava DP, Photowala H, Kai L, Cahill ME, Woolfrey KM, Shum CY, Surmeier DJ, Penzes P. 2007. Kalirin-7 controls activity-dependent structural and functional plasticity of dendritic spines. Neuron 56: 640-656.

Yamagata M, Sanes JR, Weiner JA. 2003. Synaptic adhesion molecules. Curr Opin Cell Biol 15: 621-632.

Yasumatsu N, Matsuzaki M, Miyazaki T, Noguchi J, Kasai H. 2008. Principles of long-term dynamics of dendritic spines. J Neurosci 28: 13592-13608.

Yuste R, Bonhoeffer T. 2004. Genesis of dendritic spines: insights from ultrastructural and imaging studies. Nat Rev Neurosci 5: 24-34.

Zhou L, Martinez SJ, Haber M, Jones EV, Bouvier D, Doucet G, Corera AT, Fon EA, Zisch AH, Murai KK. 2007a. EphA4 signaling regulates phospholipase $\mathrm{C} \gamma 1$ activation, cofilin membrane association, and dendritic spine morphology. J Neurosci 27: 5127-5138.

Zhou P, Porcionatto M, Pilapil M, Chen Y, Choi Y, Tolias KF, Bikoff JB, Hong EJ, Greenberg ME, Segal RA. 2007b. Polarized signaling endosomes coordinate BDNF-induced chemotaxis of cerebellar precursors. Neuron 55: 53-68.

Ziv NE, Smith SJ. 1996. Evidence for a role of dendritic filopodia in synaptogenesis and spine formation. Neuron 17: $91-102$. 


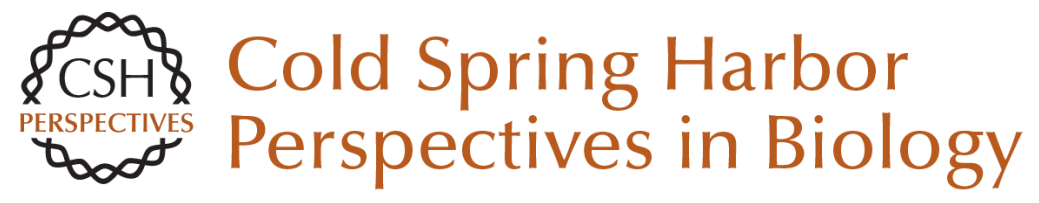

\section{Guidance Molecules in Synapse Formation and Plasticity}

Kang Shen and Christopher W. Cowan

Cold Spring Harb Perspect Biol 2010; doi: 10.1101/cshperspect.a001842 originally published online March 10, 2010

\section{Subject Collection Neuronal Guidance}

Mechanisms and Molecules of Neuronal Wiring: A Primer

Alex L. Kolodkin and Marc Tessier-Lavigne

Guidance Molecules in Axon Pruning and Cell

Death

Pierre Vanderhaeghen and Hwai-Jong Cheng

Initiating and Growing an Axon

F. Polleux and William Snider

Navigating Intermediate Targets: The Nervous System Midline

Barry J. Dickson and Yimin Zou

Cellular Strategies of Axonal Pathfinding

Jonathan Raper and Carol Mason

Guidance Molecules in Axon Regeneration

Roman J. Giger, Edmund R. Hollis II and Mark H. Tuszynski

Signaling from Axon Guidance Receptors Greg J. Bashaw and Rüdiger Klein

Visual Map Development: Bidirectional Signaling, Bifunctional Guidance Molecules, and Competition

David A. Feldheim and Dennis D. M. O'Leary
Wiring the Brain: The Biology of Neuronal

Guidance

Alain Chédotal and Linda J. Richards

Guidance Molecules in Synapse Formation and

Plasticity Kang Shen and Christopher W. Cowan

The Growth Cone Cytoskeleton in Axon

Outgrowth and Guidance

Erik W. Dent, Stephanie L. Gupton and Frank B. Gertler

Topographic Mapping--The Olfactory System Takeshi Imai, Hitoshi Sakano and Leslie B. Vosshall

Self-avoidance and Tiling: Mechanisms of

Dendrite and Axon Spacing Wesley B. Grueber and Alvaro Sagasti

Trafficking Guidance Receptors Bettina Winckler and Ira Mellman

Axon Guidance Molecules in Vascular Patterning Ralf H. Adams and Anne Eichmann

Human Genetic Disorders of Axon Guidance Elizabeth C. Engle

For additional articles in this collection, see http://cshperspectives.cshlp.org/cgi/collection/

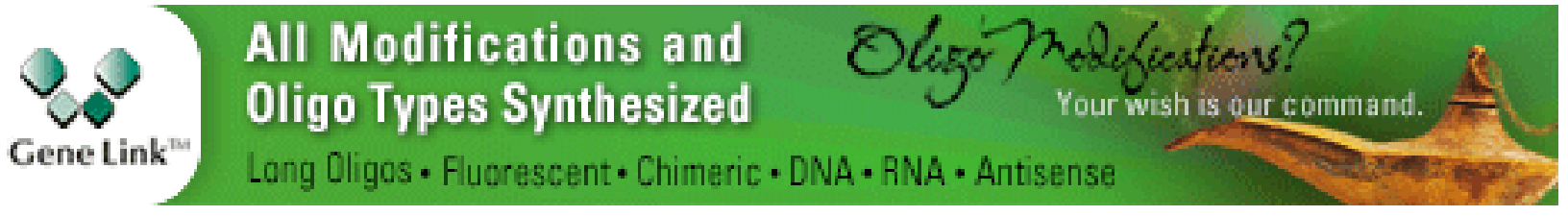

Copyright @ 2010 Cold Spring Harbor Laboratory Press; all rights reserved 